\title{
Mapping Discourses of Climate Change Adaptation in the United Kingdom
}

\author{
MATTHEW COTTON \\ Department of Environment, University of York, Heslington, York, United Kingdom \\ EMMA STEVENS \\ Department of Urban Studies and Planning, University of Sheffield, Sheffield, United Kingdom
}

(Manuscript received 14 March 2018, in final form 24 July 2018)

\begin{abstract}
The concept of adaptation is becoming part of mainstream public discourse on climate change. Yet the diversity, complexity, and novelty of the adaptation concept itself leads to interpretive flexibility, differing public understanding of (and engagement with) adaptation strategies, and hence differentiated policy responses. The boundary work of communicative practices and public understanding of the adaptation concept therefore requires empirical analysis in different cases and contexts. This study employs Q-methodology (a combined quantitative-qualitative social research method) to reveal the typologies of perspectives that emerge around the adaptation concept among a diverse group of citizen-stakeholders in the United Kingdom. Four such typologies are identified under the labels 1) top-down climate action, 2) collective action on climate change, 3) optimistic, values-focused adaptation, and 4) adaptation skepticism. The division between these perspectives reveals a perceived "responsibility gap" between the governmental-institutional and/or individual-community levels. Across the emergent discourses we find a consensual call for a multisector, multiscalar, and multistakeholder-led approach that posits adaptation as a contemporary, intragenerational problem, with a strong emphasis upon managing extreme weather events, and not as an abstract future problem. By attending to these public discourses in climate policy, this presents a potential means to lessen such a responsibility gap.
\end{abstract}

\section{Introduction-Adapting to climate change}

Adaptation is a process by which human actors as individuals, communities, regions, and national or transnational entities act to cope with the consequences of climate change. Even with rapid greenhouse gas emission stabilization/reduction globally, the long reaction times within climate systems mean that global temperatures will still increase, requiring remedial actions to ameliorate emergent negative environmental and socioeconomic impacts. This necessitates combined technical and societal responses to reduce systemic vulnerability to climate variability effects.

Despite potential benefits such as longer growing seasons in cooler countries (e.g., Linderholm 2006) or more efficient shipping routes through an ice-free Arctic (Smith and Stephenson 2013), the negative impacts of climate change are significant and far reaching. These include

Corresponding author address: Matthew Cotton, matthew.cotton@ york.ac.uk (but are not limited to) increased incidence/intensity of extreme weather events (Stott et al. 2016), biodiversity redistribution and loss (Pacifici et al. 2015; Pecl et al. 2017), extinction risks (Urban 2015), disruption to ecosystem services (Geneletti and Zardo 2016; Lavorel et al. 2015), heat stress (Deryng et al. 2014; Lindberg et al. 2016; Voskamp and Van de Ven 2015), drought (Trenberth et al. 2014), sea level rise and coastal flooding (Carson et al. 2016; Clark et al. 2016), fluvial and pluvial flooding (Arnell and Gosling 2016; Kaspersen et al. 2017; Kundzewicz et al. 2014), ocean acidification (Boyd et al. 2015; Riebesell and Gattuso 2015) and growing resource restrictions such as loss of potable water supply (Döll et al. 2015; Khan et al. 2015), crop failure (Challinor et al. 2014), associated negative socioeconomic effects from supply disruption within infrastructure networks (Chappin and van der Lei 2014), and negative impacts upon public health (Watts et al. 2015).

Climate change affects multiple aspects of human economic and social activity, but the impacts are (or will be) highly differentiated by sector (agriculture, infrastructure, 
marine management, flood defense, etc.) and will affect different countries, regions, communities, and individuals in multiple ways based upon their vulnerability and relative adaptive capacity. It is important for decision-makers to question the extent to which adaptation reduces the risks of climate change, what policies are needed, and how can they best be developed and applied (Burton et al. 2002). This requires knowledge of how adaptation choices are made under conditions of resource constraint and uncertainty and knowledge of how existing policies can be amended or "climate proofed" (Urwin and Jordan 2008) while avoiding the risks of maladaptation, involving actions or initiatives that foster short-term gains but insidiously affect systems' long-term vulnerability and/ or adaptive capacity to climate change over the longer term (Barnett and O'Neill 2010). This picture is further complicated by the fact that adaptation pathways are mediated by the relative sociopolitical, cultural, and economic status of different actors involved (Brooks et al. 2005). They are context specific-there is no single adaptation response that can cover all outcomes in all cases. It is therefore necessary for adaptation strategies to be sensitive to the underlying political and cultural roots of such actions (Pelling 2010). Adger (2003) argues, therefore, that adaptation is best understood as a dynamic social process: one that is commonly understood to require a localized, bottom-up, place-based, and coproduced approach to be successful (Lo and Jim 2015; Meadow et al. 2015; Rayner 2010; van Aalst et al. 2008).

\section{Adaptation as a matter of public perception and environmental communication}

The influence of public perceptions in shaping policy preferences and individual adaptation outcomes is an important aspect of climate change politics. However, the question of how to take into account heterogeneous public and stakeholder values, perceptions, and concerns in a local, bottom-up, and coproduced manner remains fraught with communicative barriers. Whether at the level of policy-making or individual action, the question of how to adapt is subject to framing effects, in which choices are influenced by the way in which the problem is conceptualized and presented to decision-makers (Chong and Druckman 2007; Frisch 1993; Lakoff 2010; McEvoy et al. 2010; Nisbet 2009; O'Brien et al. 2007). Perceptions of everything from changes to local weather patterns to the validity of long-term climate forecasts are subject to cultural biases and political ideology (Goebbert et al. 2012; Hulme 2009; McNeeley and Lazrus 2014). In practice, adaptation research and policy are, as Adger et al. (2013) note, primarily focused upon the material aspects (such as technological solutions, or quantifiable impacts to ecosystems or livelihoods), yet the so-called softer social and cultural aspects have been less thoroughly researched and integrated into policy.

One specific social dimension of adaptation concerns environmental communication and broader public engagement with the concept itself. Adaptation has received relatively little coverage in print and televised media as discourses surrounding the mitigation of high-impact/ low-probability climate impacts have remained dominant (Anderson 2009; Boykoff 2007). Although within climate change policy and planning something of an adaptationmitigation dichotomy has emerged (Biesbroek et al. 2015; Moser 2012), the two concepts are principally scientific constructs and so nonexpert citizens may not perceive them as mutually exclusive. For example, both terms can be conflated or confused (Moser 2014) or else mutually framed within public discourse within a wider sustainability umbrella (Chilvers et al. 2014). There is therefore, as Moser (2014) argues, a need to communicate specific adaptation risks and realities to multiple stakeholder audiences in a more effective way.

Although there is a pressing need for better adaptation communication, climate communicators encounter numerous barriers to effective engagement (Lorenzoni et al. 2007; Moser and Ekstrom 2010). Such barriers include (a relative lack of) stakeholder awareness, problems of scientific uncertainty around the estimates of future greenhouse gas emissions and in projections of future climate impacts, and the relative psychological/ spatial/temporal distance through which many in developed countries perceive climate change (Spence et al. 2012), as well as communication resource constraints and a lack of underlying political commitment (Clar et al. 2013; Eisenack et al. 2014). Commonly cited solutions include conducting awareness-raising activities and closing knowledge gaps through decision-support frameworks (Clar et al. 2013). Yet, as Storbjörk (2007) notes, there is persistent confusion over what the term "adaptation" encompasses and what it hopes to achieve; although low public awareness about adaptation is associated with a lack of action, simply disseminating knowledge about climate change impacts, vulnerabilities, and adaptive capacity is unlikely to remove existing barriers to adaptation and lead to positive action (Archie et al. 2012; Moser and Ekstrom 2010). The conceptual complexity of adaptation produces heterogeneous mental models of its nature and impacts among diverse stakeholder groups (Otto-Banaszak et al. 2011); because adaptation incorporates a huge array of actions carried out across a wide variety of settings by a number of different actors under different institutional and scalar governance constraints, multiple-stakeholder engagement with citizens, 
public bodies and interest groups, businesses, and government organizations involves a wide differentiation of responsibilities within each of these interested parties (Adger et al. 2005).

We can conclude from this problem of adaptation communication that "success" is subject to a negotiation among competing stakeholder interests, with each having differing conceptions of the core concept. This means that adaptation is essentially a type of boundary work (Gieryn 1999), in the sense that the conceptual plasticity of adaptation involves socially constructed demarcation of adaptation concepts and practices and the negotiation of these at multiple geographic and governance scales. It is necessary, therefore, to present climate change adaptation in a way that is meaningful to nonexperts and to avoid engagement within a narrow bounded rationality that focuses solely upon scientific issues (particularly because framing climate change in adaptation terms may be more engaging for individuals who show low concern for climate change overall; see Howell et al. 2016). To mobilize knowledge about adaptation in a way that is credible, salient, and politically legitimate, what is required is a more citizen-centered examination of adaptation perceptions and issues (Leith 2011) to better explore multiple definitions and meanings. It is this boundary work, exploring the conceptual plasticity of adaptation and how it is discursively demarcated, that is under consideration in this empirical study. We suggest that, given the relative novelty of the climate adaptation concept in broader public debate among citizenstakeholders (and hence the potential for the public's differentiated and complex interpretations of it), and given the lack of media coverage and policy debate on the topic, further qualitative exploration of subjective representations is necessary to better understand typologies of heterogeneous citizen-stakeholder perspectives on the issue (and hence inform adaptation communication practices). In this empirical social scientific study of adaptation among citizen-stakeholders in the United Kingdom, we apply a mixed-method qualitativequantitative approach termed "Q-methodology" to explore this conceptual diversity, and we report upon the relevance of these findings for climate adaptation communicative practice. Q-methodology has shown considerable value in exploring subjective perspectives on a range of environmental management issues encompassing energy (Cotton and Devine-Wright 2011; Cuppen et al. 2010; Venables et al. 2009), forestry (Steelman and Maguire 1999), and agriculture and conservation (Bumbudsanpharoke et al. 2009). The method has also been applied in climate change (principally mitigation) perceptions and engagement research in recent years (Burke et al. 2018; Lo 2016;
O'Neill and Nicholson-Cole 2009; O'Neill et al. 2013), and this study aims to complement these findings through a specific emphasis on adaptation discourse within this broader field.

\section{Understanding public perspectives on climate adaptation-A role for Q-methodology}

Q-methodology (hereinafter referred to as Q-method) is a specialist social research method that was designed by Stephenson (1953) as a means to analyze subjective opinion (Cross 2005). Q-method quantitatively maps subjective attitudes and opinions, rendering them open to statistical analysis. It enables researchers to identify a number of discourses (sometimes referred to as idealized accounts) around a topic. Unlike social survey methods that impose specific categories against which attitudes are measured, Q-method examines subjectivity from the standpoint of the person experiencing it (Brown 1996). It is in this way that we use the method for the study of the boundary work of the climate adaptation conceptit combines quantitative and qualitative techniques to reveal the relevant types of perspective in a population rather than the prevalence of such types. It is therefore valuable in explaining how and why people think the way that they do about climate adaptation rather than counting how many people think one way or another (see, e.g., Tielen et al. 2008).

Although statistical in nature, Q-method is consistent with postpositivist social scientific analysis (Durning 1999), particularly in relation to the analysis of discourse [see Dryzek (1990) for examination of this point]. As Cotton (2015) suggests, Q-method has value in its capacity to mediate between the microdiscursive realm of individual statements of belief and social practices, and the macrodiscursive realm of broader social and environmental discourses. Using Q-method allows us to link individual stakeholder perspectives to broader debate within civil society on the management of climate adaptation. Thus Q-method is chosen, as Dasgupta (2005) suggests, because it is highly suited to researching adaptation as a social phenomenon around which there is conceptual novelty, debate, conflict, and contestation.

\section{Q-method in practice}

In this Q-method study, we follow a five-stage research plan wherein we do the following:

1) define a concourse,

2) select the statements for "Q-sorting,"

3) select a participant sample ("P-sample"),

4) Q-sort the statements, and

5) analyze and interpret the results. 


\section{a. Defining a concourse}

A concourse refers to "the flow of communicability surrounding any topic" (Brown 1993) - the concourse encapsulates the range of positions taken on the climate change adaptation concept. It is ultimately from this concourse of ideas that Q-method collates and correlates individual responses and extracts idealized forms of discourse latent in the data provided by the individuals in the study (Brown 1996; McKeown and Thomas 1988). The concourse is a collected set of statements from which we draw a representative sample (Watts and Stenner 2012). This collected set was gleaned by using Boolean search operators within well-known databases (Google, Google Scholar, Scopus, Web of Knowledge, and Nexis) in sequence: "climate change adaptation," then searches with "climate change adaptation" AND operator for "strategy OR strategies," "media," "social," "perception OR perceptions," "policy OR policies," "responsibility OR responsibilities," and "individual OR individuals." These searches produced a series of secondary sources to form a ready-made Q-sample, drawing statements (primarily) from academic, nongovernmental-organization, policy-document, weblog, and activist written sources (we collected 210 statements in total for the complete concourse).

An inductive content analysis of the findings was used to code the retrieved documents and generate statement categories through which to sample statements used in the Q-sort process. The content analysis allowed us to alternate between specific categories and emergent relationships within the corpus of materials and also to quantify and categorize the text responses that form the raw material for the processes of selecting statements for subsequent Q-sorting.

\section{b. Selecting the statements for $Q$-sorting}

As Brown (1993) suggests, the selection process for those statements to be included remains "more art than science." The statements collected were selected to encapsulate the various standpoints and cover as many subissues within the topic as possible so that the participants can truly express their views. It must be noted that it is only when the participants are sorting the statements that they become imbued with meaning (Watts and Stenner 2012). However, it behooves Q-researchers to provide structure to the selection to ensure that obvious biases within the corpus of materials can be eliminated or ameliorated. This is done by forcing the researcher to select a wide variety of statements in order to make the Q-set broadly representative.

In practice, we selected a subset of statements from the concourse for presentation to the participants (the
“Q-sample," or sometimes “Q-set"). Structuring the Q-sample introduces some overt bias in statement selection, and then, because it is ultimately the researcher who makes the selection of statements deemed relevant, different researchers would make different selections from the same concourse (van Exel and de Graaf 2005). Wording may also differ, so we piloted the statement set with student participants (not included in the final dataset) specifically on wording. Note that ambiguity of the statements is not in itself a problem. This is because participants give their own meaning to the statements based on where they are sorted and they will interpret statements in their own way (Coogan and Herrington 2011). We expect, therefore, as Thomas and Baas (1992) argue, that different statements constructed in different ways from the same concourse will still produce similar conclusions. This is because the Q-method operation is subjective and represents an individual's point of view; there is no external criterion for evaluating an individual's response to a particular statement; thus, each individual's set of rank-ordered statements is deemed a valid expression of his or her opinion (Brown 1993).

To select statements, we followed a procedure similar to that of McLaughlin and Cutts (2018). First, we developed the concourse of statements. Second, we thematically coded the statements into five overarching themes, based on a reasonable assessment and interpretation of each statement. Third, duplicate and confusing statements were eliminated from the initial concourse. Fourth, another statement elimination process was conducted from feedback collected from a mock pilot study with students. Fifth, statements were randomly eliminated from each theme to maintain equal statement counts within each theme for a Q-set total of 34 statements. Sixth, the selected Q-set was independently checked by an academic not involved in this study. Seventh, the set was discussed between authors to ensure that they were "unambiguous, non-contentious, and comprehensive" (Spurgeon et al. 2012) to ensure balance, breadth, and applicability to the issue of climate change adaptation. The statements were then numbered and printed on cards in preparation for the Q-sort. The thematic analysis categories and some example statements (unedited) are listed below:

\section{- Theme: Potential impacts and outcomes}

- Statement 13: The implementation of climate change adaptation strategies will alter my lifestyle significantly.

- Statement 25: Adapting to climate change will be detrimental to economic growth and opportunity.

- Theme: Technologies and strategies

- Statement 8: Adaptation to climate change should be focused on traditional, hard techniques such as structural adjustments e.g., sea walls to combat rising sea levels. 
- Statement 9: Adaptation strategies and mitigation strategies must complement one another.

- Theme: Responsibilities (political and moral)

- Statement 5: Climate change adaptation strategies will disproportionately affect the world's poorest people.

- Statement 34: Climate change adaptation must be a collaborative effort and must involve a range of stakeholders (e.g., general public, business sector, local government, national government).

- Theme: Knowledge, perception, and awareness

- Statement 7: I am concerned about the melting of the polar icecaps.

- Statement 19: Climate change has dropped off the agenda.

- Theme: Limitations and barriers

- Statement 6: When barriers, such as technological requirements and financial limitations, are overcome then society will be able to successfully adapt to a changing climate.

\section{c. Selecting a participant sample}

In our study, as in other Q-method case studies, a comparatively small number of participants is desirable (when compared with R-method surveys). Brown (1980) argues that "all that is required are [sic] enough subjects to establish the existence of a factor for purposes of comparing one factor to another." The underlying premise of the method is that within a community there are fewer ways of thinking of a given topic than there are people (Neff 2014). Consequently, the number of participants in the "P-set" is typically smaller than the number of statements in the Q-sample. As in a range of similar environmental social science studies using Q-method (Cuppen et al. 2010; Steelman and Maguire 1999; Wolsink 2010) our participant sampling (P-sample) was intended to represent diversity of knowledge, experiences, and hence perspectives among citizen-stakeholders: in essence those who are likely to have a distinct viewpoint on the problem in hand, which will in turn give meaning to their responses (Robbins and Kreuger 2000). However, as Watts and Stenner (2005) suggest, it is better under such circumstances to avoid a priori assumptions that are based upon preconceived demographic categorization. Q-method allows individuals to self-categorize on the basis of the item configurations they produce, so opportunistic or purposive sampling techniques are recommended over random sampling in the manner of an R-survey (Brouwer 1999).

During the period May-July 2015, 30 returned Q-sorts from a geographically and professionally diverse group of citizen-stakeholders constitute the primary data for this study. The age range for the purposively sampled P-set was 18-68 (17 males and 13 females). Some Q-sorts were conducted face to face and others were done by mail (although this is not expected to yield a difference in result; see Tubergen and Olins 1979). A variety of professional backgrounds including both "lay" (nonspecialist) perspectives as well as those with specific stakeholder interests related to climate change adaptation outcomes, including environmental, local government, urban and transport planning, public health, and agriculture knowledge/experience, were represented. Details are shown in the second column of Table 1.

\section{d. Q-sorting}

The participants Q-sorted the statements according to the condition of instruction (van Exel and de Graaf 2005); that is, they sorted the cards from most like my opinion ( +4$)$ to least like my opinion $(-4)$, with 0 being neutral. As is common in Q-method studies, respondents were instructed to adhere to a predetermined (in this case, forced quasi-normal) distribution. It is customary to conduct a short postsort questionnaire to allow participants to reflect and further define their position on the statements within the Q-sort. We altered this protocol by instructing participants instead to annotate the back of each of the statement cards and to write down their reflections upon each Q-sort statement, thereby allowing personal sorter reflections to be easily traceable back to each of the Q-set items. Examples of these short statements are included as qualitative data in the discussion section to further contextualize the Q-sorts, paying specific attention to the comments related to Q-statements that define factors and to the responses of those Q-sorters whose positions strongly correlate with the associated factor (as indicated in Table 1). Where participants' reflections are included, their written responses are labeled $\mathrm{P \#}$.

\section{e. Analysis and interpretation of results}

Complete Q-sorts were analyzed using PQMethod software (http://schmolck.org/qmethod/). A correlation matrix of all Q-sorts was subject to factor analysis (in this case, principal components analysis). A four-factor solution was retained that explained $62 \%$ of total variance. The four-factor solution was chosen because each factor was statistically significant with an eigenvalue $>1.00$, with at least two Q-sorts loading on each factor (factors 5+ did not meet these two criteria). The four factors were then rotated using varimax rotation, which seeks to ensure that each Q-sort had a high factor loading to only one of the study factors and that the factors are positioned in such a way that the final solution maximizes the amount of study variance explained. Participant loadings on factors are shown in Table 1. Participants (each individual Q-sort) are numbered from 1 to 30 . Loadings 
TABLE 1. Participant loadings on factors. Numbers in boldface type represent a defining sort for that factor.

\begin{tabular}{|c|c|c|c|c|c|}
\hline Q-sort No. & Sorter details & Factor 1 & Factor 2 & Factor 3 & Factor 4 \\
\hline 1 & Consultancy, F, 30-39 & 0.6901 & 0.2278 & 0.4433 & 0.2324 \\
\hline 2 & No profession, F, 18-29 & 0.3847 & 0.3737 & -0.0449 & 0.5246 \\
\hline 3 & Research, F, 30-39 & 0.3651 & 0.5802 & 0.2909 & 0.1594 \\
\hline 4 & Civil service, F, 40-49 & 0.6856 & 0.3746 & 0.2685 & -0.0392 \\
\hline 5 & Farming, M, 50-59 & 0.6054 & -0.0687 & 0.3629 & 0.3196 \\
\hline 6 & Transport planning, F, 18-29 & 0.2136 & -0.2179 & 0.1054 & 0.7210 \\
\hline 7 & Public sector, M, 40-49 & 0.8323 & 0.0200 & -0.2204 & 0.0326 \\
\hline 8 & Urban planning, M, 18-29 & 0.7087 & -0.0065 & 0.2745 & 0.2278 \\
\hline 9 & Logistics, M, 18-29 & -0.0347 & 0.4462 & -0.1897 & 0.6846 \\
\hline 10 & Technical support, M, 18-29 & 0.2466 & 0.2530 & 0.4630 & 0.0184 \\
\hline 11 & Sales, M, 18-29 & 0.2444 & 0.4343 & 0.0882 & 0.6261 \\
\hline 12 & Retired, M, 60+ & 0.2764 & 0.6875 & -0.0047 & 0.0721 \\
\hline 13 & Consulting, F, 18-29 & 0.1954 & 0.4536 & 0.5104 & 0.3646 \\
\hline 14 & Retired, M, $60+$ & 0.5063 & 0.1433 & 0.4134 & 0.3513 \\
\hline 15 & Public sector, F, 18-29 & 0.0874 & 0.8538 & 0.1403 & 0.1468 \\
\hline 16 & Environment sector, M, 30-40 & 0.4917 & 0.4429 & 0.2912 & 0.3398 \\
\hline 17 & Property surveying, M, 18-29 & 0.6062 & 0.2402 & 0.0873 & 0.2166 \\
\hline 18 & (No data) F, (no data) & 0.5059 & 0.3452 & 0.1094 & 0.1680 \\
\hline 19 & Public sector, F, 50-60 & 0.1618 & 0.1235 & 0.6151 & 0.2151 \\
\hline 20 & Retired, M, 60+ & 0.6840 & 0.2970 & 0.3332 & 0.1357 \\
\hline 21 & In higher education, $\mathrm{F}, 18-30$ & 0.7210 & 0.1354 & -0.1045 & 0.0097 \\
\hline 22 & (No data) F, (no data) & -0.0443 & -0.0110 & 0.3481 & 0.5638 \\
\hline 23 & Health service, $M, 50-60$ & 0.1058 & -0.0795 & -0.6477 & 0.0507 \\
\hline 24 & Engineer, M, 50-60 & 0.1376 & 0.9047 & 0.2144 & 0.0458 \\
\hline 25 & Civil service, M, 30-40 & -0.2025 & -0.3940 & 0.1747 & -0.7966 \\
\hline 26 & Retired, M, $60+$ & -0.1211 & 0.1517 & 0.7580 & 0.0791 \\
\hline 27 & Teaching, F, 30-40 & 0.6784 & 0.2952 & 0.2563 & 0.3457 \\
\hline 28 & $\begin{array}{l}\text { Small-to-medium-enterprise manager, } \\
\quad \mathrm{M}, 40-50\end{array}$ & 0.3763 & 0.2417 & 0.5731 & -0.0452 \\
\hline 29 & Public health, F, 30-40 & 0.2798 & 0.4953 & -0.0511 & 0.3037 \\
\hline 30 & Teaching, F, 60+ & 0.7475 & 0.4855 & 0.1919 & -0.1478 \\
\hline
\end{tabular}

on factors are highlighted in boldface to show defining sorts for that factor, that is, the exemplars that reveal the shared item pattern or configuration that is characteristic of that factor (Watts and Stenner 2012).

We interpret the factors as a series of summarizing accounts, each of which aims to explain the viewpoint being expressed by each factor and hence produce an ideal or aggregated perspective (which we refer to as a discourse). Each discourse is an interpretation of positions expressed within the Q-sorting process, constructed by careful reference to the positioning and overall configuration of the items in the relevant best-estimate factor arrays (Watts and Stenner 2012). In interpreting the discourses, we followed Stevenson's (2015) and Cuppen et al.'s (2010) method: we examine statements that have the highest and lowest scores for each factor (statements ranked at +4 and -4 for each factor) to set the context of the discourse, combined with discussion of the distinguishing statements (i.e., statements that were ranked significantly differently between a given factor and all other factors, and the statements that were not ranked differently by any factors; see Webler et al. 2009).
Table 2 shows the list of statements and factor Q-sort values for each. In the narrative description statements, numbers are indicated alongside the Q-sort value score in the composite factor array; e.g., (s10, $\left.-4^{*}\right)$ indicates that statement number 10 loaded at -4 (least like my perspective). The distinguishing statements for each factor that are marked with a caret are significant at $P<$ 0.05 ; statements marked with an asterisk are significant at $P<0.01$.

Each factor is given a moniker or label to summarize the salient features of the account. Discourse 1 is "topdown climate action," discourse 2 is "collective action on climate change," discourse 3 is "optimistic, values-focused adaptation," and discourse 4 is "adaptation skepticism."

\section{1) Discourse 1: Top-Down Climate ACTION (D1)}

The context to this discourse is that climate change is deemed by proponents to be an urgent, deeply significant, and personal issue that cannot be ignored (and that they would not want to ignore) (s27, -4). Specific threats/ negative climate change impacts such as extreme weather 
TABLE 2. Q-sort statements (unedited) and factor (1-4) arrays. A caret indicates statements that are significant at $P<0.05$, and an asterisk marks those that are significant at $P<0.01$.

\begin{tabular}{crrrr}
\hline \hline Statement & 1 & 2 & 3 & 4 \\
\hline 1. In the long term, adaptation strategies & +2 & +3 & +2 & +3
\end{tabular}
alone may not be sufficient to cope with all the projected impacts of climate change.

2. There are always other costs that the $\begin{array}{llll}-1 * & -3^{*}-4^{\wedge} & 0^{*}\end{array}$ government should prioritise over adapting to climate change e.g., the economy, welfare concerns.

3. The only power to make real decisions $+2^{*}+3^{*}-2 \quad-3$ about climate change adaptation is achieved through policy at a national government level.

4. Engagement with the public on potential climate change adaptation is the responsibility of local agencies (e.g., local gov. and local industries/ businesses) to engage with the public.

5. Climate change adaptation strategies will disproportionately affect the world's poorest people.

6. When barriers, such as technological requirements and financial limitations, are overcome then society will be able to successfully adapt to a changing climate.

7. I am concerned about the melting of the polar ice caps.

8. Adaptation to climate change should be focused on traditional, hard techniques such as structural adjustments e.g., sea walls to combat rising sea levels.

9. Adaptation strategies and mitigation strategies must complement one another.

10. An average global temperature increase of four degrees by the end of the century is something that humanity can adapt to.

11. 'Climate change adaptation' is a loosely defined term.

12. I think that the potential effects of climate change have been exaggerated by the media and other outlets.

13. Other problems that society is currently facing could be worsened if government policy prioritises climate change adaptation e.g., economic recovery may be hindered.

14. Adapting to the effects of change is a good idea in theory but it will never have a real world impact on climate as an issue.

15. The implementation of climate change adaptation strategies will alter my lifestyle significantly.

16. As humans continue to develop, individuals and groups need to prioritise their own values to meet the requirements for adapting to climate change. $\begin{array}{llll}-1 & -1 & -3^{*} & -1\end{array}$
TABLE 2. (Continued)

\begin{tabular}{ccccr}
\hline Statement & 1 & 2 & 3 & 4 \\
\hline 17. A successful strategy of adaptation & 0 & +1 & 0 & -2
\end{tabular}

is only achievable when there is full

understanding of who is or could

become vulnerable.

18. The values of individuals will have $\quad \begin{array}{llll}+1 & 0 & +4 & +1\end{array}$ a significant influence on the success of potential climate change adaptation strategies.

19. Climate change has dropped off the $\begin{array}{lllll}-3 & -3 & -1 & -4 *\end{array}$ agenda

20. Strategies to adapt to climate change $\begin{array}{llll}-1 & +2 & +3 & -1\end{array}$ will be most effective in the local, community setting.

21. I am unsure what strategies fall under the term of 'climate change adaptation'.

22. As climate changes, the probability of extreme weather events will increase (e.g., extreme flooding, droughts and storms).

23. Planning for adaptation to climate $+1+1 \quad 0 \quad 0$ change is not a new thing.

24. In order for climate change adaptation $\begin{array}{lllll}+1 & -1 & -3 & +1\end{array}$ strategies to be wholly worthwhile they must actively seek to achieve additional benefits as well as adapting to climate change (e.g., job creation).

25. Adapting to climate change will be detrimental to economic growth and opportunity.

26. Successful adaptation is an absolute necessity in addressing the problem of climate change.

27. I would prefer to ignore climate change as an issue.

28. There is a lack of urgency at an international level with regards to addressing climate change as an issue.

29. The United Kingdom has the capabilities to adapt to the effects of climate change.

30. Any successful attempts to address $\quad-2 \quad+2 \hat{2}+4 \quad-2$ climate change must begin with individuals (at a community level).

31. It is the role of the government to $+2^{*}+3^{*}-1 \quad-1$ remove any barriers to climate change adaptation strategies (such as financial limits and technological requirements).

32. We need to clearly prioritise the type $+1 \quad+1 \quad 0 \quad+2$ of adaptation strategies that are being implemented e.g., flood management vs heat stress.

$\begin{array}{cccc}-3 & 0 & -3 & +2 \\ 0 & -1 & 0 & -3 \\ 0 * & -2 & +3 & -3 \\ & & & \\ 0\end{array}$

\begin{tabular}{|c|c|c|c|}
\hline-1 & -2 & -2 & 0 \\
\hline$+3 \hat{~}$ & $-4 \hat{~}$ & +1 & +1 \\
\hline-4 & -2 & -1 & -4 \\
\hline+3 & $-2 \hat{}$ & $+1 \hat{\imath}$ & +3 \\
\hline 0 & 0 & +2 & +1 \\
\hline-2 & $+2 \hat{}$ & $+4 \hat{\imath}$ & -2 \\
\hline$+2 *$ & $+3^{*}$ & -1 & -1 \\
\hline+1 & +1 & 0 & +2 \\
\hline$-2^{\wedge}$ & $+2 *$ & $+1^{*}$ & +4 \\
\hline+4 & +4 & $+1 \hat{1}$ & +4 \\
\hline
\end{tabular}

33. The focus should always remain on climate change mitigation strategies rather than adaptation strategies.

34. Climate change adaptation must be a collaborative effort and must involve a range of stakeholders (e.g., general public, business sector, local government, national government). 
events (flood, drought, and storms) are believed to be a significant risk $(\mathrm{s} 22,+4)$; and the reporting of these threats from climate change in the media is not exaggerated or amplified (s12, -4$)$, implying a true representation of the risks involved. In terms of the response to these threats, it is noteworthy that this account does not prioritize mitigation measures over adaptation $(\mathrm{s} 33,-2 *)$, as P10 qualifies:

I believe that this (mitigation prioritization) is true in a perfect world but we have possibly already passed a tipping point, therefore we have to plan to adapt just as much as we should to mitigate (in relation to S33).

This implies that proponents of this discourse advocate a holistic approach to the climate change issue, noting that adaptation is an essential component $\left(\mathrm{s} 26,+3^{*}\right)$ of climate change strategy. However, when it comes to extreme climate change impacts (defined as those that related to warming scenarios of $4^{\circ} \mathrm{C}$ or greater), adaptation is construed as contributing to or detracting from the urgency of the issue overall $\left(\mathrm{s} 10,-3^{*}\right)$.

With regard to the management responsibilities, it is significant that, although across all discourses there is support for multistakeholder collaboration across multiple scales of public-sector, private-sector, and civilsociety interest, this viewpoint indicates a preference for government-level responsibility in adaptation and mitigation planning decisions $(\mathrm{s} 3,+2 *)$ specifically as they relate to government incentivization to remove financial barriers to adaptation planning and encourage technological development strategies $(\mathrm{s} 31,+2)$ as opposed to a focus upon the individual $(\mathrm{s} 30,-2)$ and individual values $(\mathrm{s} 16,0 *)$. P26 states,

I'm not sure how I prioritise my values. Certainly I think about my family first (in relation to statement 16).

In summary, this discourse represents a perspective that is sure of the risks posed by anthropogenic climate change, and the urgency for personal and political action in relation to this perceived threat. However, this personal concern with the climate change issue (in its broadest sense) translates into a call for more urgent and decisive action on adaptation planning, policy, and decisionmaking specifically at the international $(\mathrm{s} 28,+3)$ and national scale $(\mathrm{s} 3,+2)$ rather than individual responsibility for personal adaptation and the prioritization of (proenvironmental/proadaptation-related) personal values, in part, it appears, because the idea of personal value prioritization did not resonate with proponents of this discourse. P15 states,

Climate change is too big for individuals, and collective global action is needed at the highest level (in relation to s3).
This discourse could therefore be interpreted as a call for greater top-down intervention from government and transnational organizations in response to climate change while also emphasizing the importance and urgency of adaptation within this context.

\section{2) Discourse 2: COllective ACTION ON CLIMATE CHANGE (D2)}

Like D1, D2 is contextualized by an overarching concern for the immediacy and scale of long-term anthropogenic climate change impacts such as the increased probability and intensity of extreme weather events, flood, and drought (s22, +4); adaptation is both an issue that is urgent in terms of international political cooperation and collaboration in policy making ( $\left.\mathrm{s} 28,-2^{*}\right)$ and one that may or may not be exaggerated by media reporting of the issue $\left(\mathrm{s} 12,0^{*}\right)$. As $\mathrm{P} 4$ states,

If anything the issue has been under-exaggerated [sic] (in relation to s12).

This urgency at the international level is mirrored in other scales of climate governance. There is key emphasis upon action as a collaborative effort across different sections of civil society including government and private-sector interests $(\mathrm{s} 34,+4)$ in which individual responsibility organized at the community level has a part to play $(\mathrm{s} 30,+2 *)$. P15 states,

It's the "one person jumps nothing happens, but if one hundred people jump it's enough to make a change in noise and vibration" thing (in relation to s30).

Also in common with D1 is a concern with government playing a leading role in both adaptation-related decisionmaking $(\mathrm{s} 3,+3)$ and in the removal of financial and technological barriers to adaptation (s31, +3), with a sense that it is these barriers that must be overcome in order for adaptation to be successful $(\mathrm{s} 6,+1)$. However, there is a marked difference in the perception of adaptation as a government response to the climate change problem. D2 is distinguished as something of a pro-mitigation viewpoint disputing the necessity of adaptation as a component of broader climate change strategy (s26, -4), preferring that mitigation is prioritized over adaptation $\left(\mathrm{s} 33,+2^{\prime}\right)$. As P24 summarizes,

Mitigation will be significantly cheaper and easier in the long run than adaptation (in relation to s26).

However, it was strongly disputed that adaptation should remain the lowest priority on the government agenda $(\mathrm{s} 2,-3)$. On the whole, climate change mitigation and adaptation are both viewed as having a role, despite a lean toward mitigation. This is partly explained by a pessimism over collective/societal capacity to adapt in 
the face of severe climatic variability under high emissions scenarios $(\mathrm{s} 10,-4)$.

To summarize, this discourse represents a position that is, as with D1, concerned with urgency and potential impact of climate change yet is skeptical of encouraging action on adaptation. In part, this is explained by a position that adaptation is not possible in the face of highcost climate-related impacts such as extreme weather events, and so mitigation should be prioritized. Proponents of this perspective show a greater concern with multilevel governance at different scales of action, stressing urgency in international and national political action on climate change as a collective action problem, alongside responsibilities for stakeholders across public and private interests and individual and community-level actions on mitigation. This suggests that proponents of this discourse favor action on mitigation prioritized over adaptation and that this, in turn, is linked to a preference for multiscalar collective action solutions.

\section{3) Discourse 3: Optimistic VALUES-FOCUSED ADAPTATION (D3)}

Like D1 and D2, this perspective displays a similar emphasis upon the role of government in prioritizing climate change, asserting that economic development and other welfare issues should not be prioritized over long-term climate change policy and planning (s2, $-4 *)$ while remaining relatively neutral on the prioritization of mitigation-versus-adaptation in the policy process $(\mathrm{s} 9,0)$. There is only a slight expressed preference for mitigation $(\mathrm{s} 33,+1)$, in contrast to other discourses (D2 and D4, below). Proponents of this discourse do not perceive that involvement in adaptation planning presents an opportunity cost for society that would worsen the economy (s13, -3 ).

What differentiates this perspective is that the emphasis is clearly upon the individual and their role in adaptation responses as an expression of personal moral and sociopolitical values. Like D2, there is (in this case, very strong) support for focusing upon adaptation at the level of the individual acting within a community-level adaptation setting $\left(\mathrm{s} 30,+4^{*}\right)$. Specific to this discourse, unlike any of the others, an optimism over civil society capacity to adapt is expressed in the context of individuals prioritizing personal climate adaptation values $(\mathrm{s} 16,+3)$, who themselves will have influence upon the strategies chosen in adaptation $(\mathrm{s} 18,+4 *)$. P29 states:

Individual values need to be about compassion and respect for others less fortunate than ourselves, if we had that then we would all act on climate change (in relation to s16).

To summarize, this discourse represents an optimistic position on the adaptive capacity of the United Kingdom in the face of climate change impacts. Although it recognizes the importance of government action at national and international scales, proponents of this discourse prioritize individual action, specifically of climate changerelated values, including individual responsibility and empathy for vulnerable people, and hence seek to overcome the potential political and financial barriers to adaptation that may emerge.

\section{4) Discourse 4: AdAPtAtion SKePticism (D4)}

The context to this discourse is-like D1, D2, and D3that climate change remains on the political agenda $(\mathrm{s} 19,-4)$ and that on a personal level proponents of this discourse wish to engage with the issue rather than ignore it (s27, -4). There is a sense of being concerned with the risks that it presents to U.K. society. As seen in discourse 2, there is strong expression of a pro-mitigation preference $\left(\mathrm{s} 33,+4^{*}\right)$, as $\mathrm{P} 6$ states:

Surely we can't keep adapting to change-there has to be a point where we can't adapt (in relation to s3).

However, unlike the other discourses, there is skepticism; that is, there is a feeling that the effects of climate change have been exaggerated by media reporting on the issue $(\mathrm{s} 12,+2 *)$. This is potentially indicative of concern around media overstretch, whereby media exaggeration of dread environmental risks acts as a barrier to collective action on climate change (see, e.g., Weingart et al. 2000).

This discourse presents further skepticism of the relative value of adaptation in relation to both its perceived benefits and drawbacks. Proponents of this discourse assert that any adaptation measures put into place will have little impact upon our relative adaptive capacity to climate change $(\mathrm{s} 14,+2 *)$ or upon individual lifestyles and social practices $\left(\mathrm{s} 15,-3^{*}\right)$ in the face of such threats, linking with the reduced sense of nongovernmental actors' power demonstrated in this discourse $(\mathrm{s} 3,-3)$. As P9 states,

Mitigation of risks are [sic] a higher priority and will have a greater impact on climate change (in relation to s14).

The position presented in this discourse stands in contrast to the IPCC's assertion that sustainable development, community vulnerability, and climate change are linked; this discourse reveals expressed skepticism about the disproportionate impacts of climate change upon the world's poorest people $(\mathrm{s} 5,-2 *)$ or that assessing the vulnerability of such communities is important in adapting to climate change $\left(\mathrm{s} 17,-2^{*}\right)$. It is notably the only discourse that takes this stance on those two statements. This can be interpreted as a climate-change-affects-everyone 
stance, particularly in light of the strong assertion that climate change adaptation (and in the context of the other statements in this discourse, mitigation) must be a collaborative, multistakeholder effort $(\mathrm{s} 34,+4)$.

\section{Discussion}

As in Lo's (2016) study of climate change discourses in Hong Kong, we assert that Q-method allows us insight into the different groupings of stakeholder perspectives on climate adaptation and their sociopolitical underpinningsin essence, it reveals the ways in which heterogeneous public actors socially construct and demarcate the adaptation concept in discourse. Unlike a traditional social survey, we seek not to measure traits that are "out there" in the world but rather to determine segments of subjectivities that a person has, or groups of people have, toward a particular context or phenomenon (Hutson et al. 2010). We make no claims about the relative prevalence of adaptation perspectives or its geographic/ demographic distribution, and, as Martin (2008) asserts, there is no fundamental reason to assume that representation in terms of demographic variables would translate into representation in terms of perspectives (see also Cuppen et al. 2010).

Our use of principal components analysis of 30 Q-sorts and subsequent qualitative interpretation of the factors reveal the typologies of perspectives emergent in the debate. One feature of this analysis is to uncover the statements that do not distinguish between factors (Table 3) and those that do (Table 4). The former are indicative of discursive consensus and hence of adaptation strategies/policies/ideas that will likely encounter support (or at least little resistance) from citizenstakeholder actors. The latter are indicative of disagreement among competing stakeholder perspectives and are therefore worthy of further research and constructive multistakeholder dialogue in the development of adaptation strategy.

Certain Q-statements separate specific discourse from others. Notable in this regard is s3. We note that TopDown Climate Action (D1) and Collective Action on Mitigation (D2) indicate a preference for governmentled action with regard to climate change strategies. In the U.K. context, adaptation has been reframed in recent years as "weather resilience," "community protection," or "livelihood protection." This raises some concerns among academic and climate advocacy actors about the ability and appetite of U.K. local governments to address climate adaptation directly (Porter et al. 2015). In this context, we postulate that there are different preferences around adaptation responsibilities, specifically. Notably the division is between proponents of top-down
TABLE 3. Statements (unedited) that do not distinguish between factors (1-4). All statements are nonsignificant at $>P=0.05$.

\begin{tabular}{|c|c|c|c|c|}
\hline Statement & 1 & 2 & 3 & 4 \\
\hline $\begin{array}{l}\text { 34. Climate change adaptation must be } \\
\text { a collaborative effort and must involve } \\
\text { a range of stakeholders (e.g., general } \\
\text { public, business sector, local } \\
\text { government, national government). }\end{array}$ & +4 & +4 & +1 & +4 \\
\hline $\begin{array}{l}\text { 22. As climate changes, the probability of } \\
\text { extreme weather events will increase } \\
\text { (e.g., extreme flooding, droughts and } \\
\text { storms). }\end{array}$ & +4 & +4 & +2 & +2 \\
\hline $\begin{array}{l}\text { 1. In the long term, adaptation strategies } \\
\text { alone may not be sufficient to cope with } \\
\text { all the projected impacts of climate } \\
\text { change. }\end{array}$ & +2 & +3 & +2 & +3 \\
\hline $\begin{array}{l}\text { 23. Planning for adaptation to climate } \\
\text { change is not a new thing. }\end{array}$ & +1 & +1 & 0 & 0 \\
\hline $\begin{array}{l}\text { 19. Climate change has dropped off the } \\
\text { agenda }\end{array}$ & -3 & -3 & -1 & -4 \\
\hline $\begin{array}{l}\text { 27. I would prefer to ignore climate } \\
\text { change as an issue. }\end{array}$ & -4 & -2 & -1 & -4 \\
\hline $\begin{array}{l}\text { 8. Adaptation to climate change should be } \\
\text { focused on traditional, hard techniques } \\
\text { such as structural adjustments e.g., sea } \\
\text { walls to combat rising sea levels. }\end{array}$ & -2 & -3 & -2 & -2 \\
\hline $\begin{array}{l}\text { 13. Other problems that society is } \\
\text { currently facing could be worsened if } \\
\text { government policy prioritises climate } \\
\text { change adaptation e.g., economic } \\
\text { recovery may be hindered. }\end{array}$ & -1 & -1 & -3 & -1 \\
\hline
\end{tabular}

intervention on adaptation (proponents of D1 and D2) versus those who favor individual responsibility as a reflection of personal values (D3) and those who are simply more skeptical about adaptation as a moral hazard in relation to mitigation (D4).

The differentiation in the framing of adaptation responsibility is pertinent to ongoing debates surrounding common but differentiated responsibility in climate governance. The concept was initially applied to state interactions internationally in negotiating heterogeneous domestic greenhouse gas reduction commitments on the basis of differential development status and relative capacity to act (Rajamani 2000). Climate change responsibilities are commonly framed in the form of those who cause the problem are morally responsible for solving it, that is, the "polluter pays" principle. Yet descriptions of common but differentiated responsibility in international and domestic law do not provide a complete account of who should bear the burdens of global climate change (Caney 2005). Scholarship on adaptation responsibilities has commonly focused upon defining responsibility for impacts, fair burden sharing, and the distribution of adaptation assistance either to vulnerable countries (Paavola and Adger 2006) or to specific social groups 
TABLE 4. Statements that distinguish between factors (1-4).

\begin{tabular}{|c|c|c|c|c|}
\hline Statement & 1 & 2 & 3 & 4 \\
\hline $\begin{array}{l}\text { 3. The only power to make real decisions } \\
\text { about climate change adaptation is } \\
\text { achieved through policy at a national } \\
\text { government level. }\end{array}$ & +2 & +3 & -2 & -3 \\
\hline $\begin{array}{l}\text { 14. Adapting to the effects of change is } \\
\text { a good idea in theory but it will never } \\
\text { have a real-world impact on climate } \\
\text { change as an issue. }\end{array}$ & -3 & 0 & -3 & +2 \\
\hline $\begin{array}{l}\text { 16. As humans continue to develop, } \\
\text { individuals and groups need to } \\
\text { prioritise their own values to meet the } \\
\text { requirements for adapting to climate } \\
\text { change. }\end{array}$ & 0 & -2 & +3 & -3 \\
\hline $\begin{array}{l}\text { 26. Successful adaptation is an absolute } \\
\text { necessity in addressing the problem of } \\
\text { climate change. }\end{array}$ & +3 & -4 & +1 & +1 \\
\hline $\begin{array}{l}\text { 30. Any successful attempts to address } \\
\text { climate change must begin with } \\
\text { individuals (at a community level). }\end{array}$ & -2 & +2 & +4 & -2 \\
\hline $\begin{array}{l}\text { 33. The focus should always remain on } \\
\text { climate change mitigation strategies } \\
\text { rather than adaptation strategies. }\end{array}$ & -2 & +2 & +1 & +4 \\
\hline
\end{tabular}

(including, e.g., tribes; Whyte 2013). Yet this literature is less clear about the differentiation of responsibilities for adaptation measures at multiple scales and policy/legal domains. The most commonly cited solution is to build common responsibility among different stakeholder groups by binding them through collective action (Adger 2003) and/or through active involvement in multistakeholder adaptation planning measures (Storbjörk 2007). It is notable in our findings, therefore, that the inclusion of multiple stakeholders in adaptation planning was agreed to be important from all perspectives (s34). However, the key differences between these discourses are held in regard to the responsibility and adaptive capacity of individuals. The importance of the individual's role at the foundation of successful adaptation strategies was demonstrated within D2 and D3 (s30). Optimism about the perceived capabilities of the individual in D3 and the role of collective action is also evidenced D2. Optimistic ValuesFocused Adaptation (D3) is the only discourse that supports the idea of an individual responsibility to rethink personal values to align with adaptation priorities (s16), suggesting onus upon the individual rather than upon the state to act on adaptation. It is only D4, the Adaptation Skepticism view, that suggests that individuals should be less concerned with their own values (s16) and adaptive actions should not seek to begin at the individual or community level (s30) because there the individual level holds no power to address climate change.

Given the discursive differences in the perceived role for top-down governmental and intergovernmental authorities versus the individual, there is a potential conflict that may emerge, which we argue represents a responsibility gap if both institutional authorities and individual citizens effectively "offload" their responsibilities to the other party, so to speak. Because there is no consensus on the level and types of responsibilities that different actors at different scales hold, greater clarity is needed within policy about which stakeholders (from public institutions to citizen-stakeholders) have which responsibilities at specific geographic, institutional, and temporal scales, particularly given the overall preference for a collaborative, multistakeholder approach to the issue (s34). We see a key area of climate adaptation discourse and further action for both environmental policy research and climate policy authorities to examine the differentiated sense of responsibility between citizen-stakeholders and public authorities and, within that, a differentiated role for values in addressing the social limits to adaptation (see, e.g., Adger et al. 2009).

As noted above, the solution to a responsibility gap in adaptation is likely a collaborative one, taking place across multiple levels from government to the individual, given the consensus across discourses on this type of approach. D3 showed the weakest agreement with a collaborative multistakeholder approach, although it is more broadly "bottom up" and citizen led in its outlook toward adaptation, which is congruent with a collaborative model of citizen engagement and collective action. When combined with the agreement among the other three discourses for "top down" public-authority-led climate change (adaptation) responsibility, this reinforces the status of adaptation that is based on incremental and participatory actions rather than more centrally controlled transformative approaches (see, e.g., Wise et al. 2014), in the sense that a multistakeholder, collective focus on adaptive responsibility posits climate adaptation as a societal risk that requires collective, community, and place-based, rather than individual, action.

Of further concern is that the dichotomy of mitigationadaptation is repeated in our findings here. D1 for example expressed that climate change mitigation should not be prioritized over adaptation (s33) in contrast to the other three discourses. A preference for mitigation among D2, $\mathrm{D} 3$, and D4 is potentially grounded in a principled argument for responsibility to reduce climate change risks rather than minimize their effects. This is most clearly shown in D2 (s26). Yet preference within the mitigationadaptation dichotomy is in part related to the relative optimism shown toward the success of adaptation strategies; specifically, D1 and D3 strongly oppose the idea that successful adaptation is merely a theoretical notion (s14) and even D4, the stance of adaptation skepticism, articulated that there is some role for adaptation within 
the climate change policy response (although to a lesser degree than did D1 and D3).

The areas of contention within the viewpoints do not define the climate change adaptation discourse alone, that is, those statements that were not distinguished by any one factor. These statements are indicative of agreement on the value attributed to them across the four viewpoints and can be (tentatively) described as consensus viewpoints. Despite differences of opinion over the causes and consequences of climate change across the discourses, all demonstrated a preference to remain aware of climate change risks rather than to ignore them (s27), with D1 and D4 demonstrating this most strongly. This "awareness" centered on the risks of climate change, specifically extreme weather events (s22), which had strong agreement across the discourses, and on the idea that a collaborative multistakeholder approach is needed (s34). This is tentatively indicative of a strong pro-climatechange-action position as consensual across the accounts, in the sense that there is no strong skepticism about the scientific basis of anthropogenic climate change expressed in the accounts here. There was also agreement that adaptation alone may not be sufficient to cope with climate change (s1) and that traditional "hard" engineered strategies should not be the only type of climate adaptation response taken (s8). Collectively we can interpret this consensus as representing a collective concern for longterm climate risks, that this is imagined as a sociotechnical problem (rather than solely a technical problem)—one that requires a collaborative solution - and that this solution must involve adaptation and mitigation components (to varying degrees across the competing perspectives). There was agreement that prioritizing adaptation within policy would be unlikely to worsen any other issues that the United Kingdom was facing (s13), in essence that it was not perceived as an additional undue financial burden to society. This is potentially explained by a belief that planning for adaptation to climate change is not a novel phenomenon (s23) or one that has dropped off the agenda (S19). This has significance because previous studies of climate change perceptions reveal climate change to be perceived as a remote, future problem (see, e.g., Wolf and Moser 2011), and yet the incidence of extreme weather events and the perceptual relationship to adaptation make this appear as a more immediate problem.

We can infer that there is general support for measures to combat extreme weather-related impacts, but that these are generally perceived as contemporary issues for policy and public expenditure rather than abstract future problems (potentially evidenced by people's exposure to images of recent high-profile flooding-related events; see Capstick et al. 2015). In short, our data can be interpreted as showing that adaptation planning is perceived as being compatible with meeting the needs of current citizens (an intra-generational) rather than being a future (inter-generational) climate change problem, although the prevalence of this discursive framing through demographically representative survey work would be a fruitful line of future research.

\section{Concluding remarks}

This study has demonstrated the boundary work of the adaptation concept-exploring the range of viewpoints across citizen-stakeholders' multiple interpretations and relationships between these interpretations. This is because Q-method has the capacity to explore the contextual discursive attempts to reconcile competing understandings and definitions of the problem of climate change adaptation (see, e.g., Shackley and Wynne 1996). The issue of boundary work in climate change research has predominantly focused upon boundaries between policy and expert worlds - through the attempts by such actors to define practices around climate science to environmental policy in contrast to one another through demarcation, and other attempts to find productive cooperation across boundaries (in contrast to a model of science policy interactions that essentializes climate science as something that can be "transferred" to policy, planning, and public opinion) (Hoppe 2010). Yet given that adaptation is understood as a "bottom-up," placebased, and public-engagement-focused practice (Rayner 2010; Schreurs 2008), it is important to understand the ways in which public actors engage in boundary workhow they discursively demarcate the adaptation concept and its proposed solutions. Our research shows that across heterogeneous stakeholder perspectives (including those of lay public actors) there are key areas of agreement on the value of adaptation within broader climate policy, of a multistakeholder and "soft" social adaptation process that complements but does not replace climate mitigation at the core of environmental policy. However, although climate change is consensually posited as an issue that participants collectively wanted to "keep on the agenda" (a finding likely welcomed by advocates of climate change action), it remains the only admission of responsibility demonstrated across all four viewpoints. The discourses were split on whether this issue of adaptation was the responsibility of government to address or whether it required a more holistic approach to achieve the most successful outcome. We can conclude, therefore, that this responsibility gap within adaptation discourse between citizen-stakeholders and public authorities is an issue that requires urgent research and response from U.K. policy-makers and climate change communicators in addressing the social limits to climate adaptation. 


\section{REFERENCES}

Adger, W. N., 2003: Social capital, collective action, and adaptation to climate change. Econ. Geogr., 79, 387-404, https://doi.org/ 10.1111/j.1944-8287.2003.tb00220.x.

— N. W. Arnell, and E. L. Tompkins, 2005: Successful adaptation to climate change across scales. Global Environ. Change, 15, 77-86, https://doi.org/10.1016/j.gloenvcha.2004.12.005.

— and Coauthors, 2009: Are there social limits to adaptation to climate change? Climatic Change, 93, 335-354, https://doi.org/ 10.1007/s10584-008-9520-z.

_ _ J. Barnett, K. Brown, N. Marshall, and K. O'Brien, 2013: Cultural dimensions of climate change impacts and adaptation. Nat. Climate Change, 3, 112-117, https://doi.org/10.1038/ nclimate1666.

Anderson, A., 2009: Media, politics and climate change: Towards a new research agenda. Sociol. Compass, 3, 166-182, https:// doi.org/10.1111/j.1751-9020.2008.00188.x.

Archie, K., L. Dilling, J. Milford, and F. Pampel, 2012: Climate change and western public lands: A survey of US federal land managers on the status of adaptation efforts. Ecol. Soc., 17, 20, https://doi.org/10.5751/ES-05187-170420.

Arnell, N. W., and S. N. Gosling, 2016: The impacts of climate change on river flood risk at the global scale. Climatic Change, 134, 387-401, https://doi.org/10.1007/s10584-014-1084-5.

Barnett, J., and S. O'Neill, 2010: Maladaptation. Global Environ. Change, 20, 211-213, https://doi.org/10.1016/j.gloenvcha.2009.11.004.

Biesbroek, R., and Coauthors, 2015: Opening up the black box of adaptation decision-making. Nat. Climate Change, 5, 493-494, https://doi.org/10.1038/nclimate2615.

Boyd, P. W., S. T. Lennartz, D. M. Glover, and S. C. Doney, 2015: Biological ramifications of climate-change-mediated oceanic multi-stressors. Nat. Climate Change, 5, 71-79, https://doi.org/ 10.1038/nclimate2441

Boykoff, M. T., 2007: Flogging a dead norm? Newspaper coverage of anthropogenic climate change in the United States and United Kingdom from 2003 to 2006. Area, 39, 470-481, https:// doi.org/10.1111/j.1475-4762.2007.00769.x.

Brooks, N., N. W. Adger, and M. P. Kelly, 2005: The determinants of vulnerability and adaptive capacity at the national level and the implications for adaptation. Global Environ. Change, 15, 151-163, https://doi.org/10.1016/j.gloenvcha.2004.12.006.

Brouwer, M., 1999: Q is accounting for tastes. J. Advert. Res., 39, $35-35$.

Brown, S. R., 1980: Political Subjectivity: Applications of Q Methodology in Political Science. Yale University Press, 355 pp.

__ 1993: A primer on Q methodology. Operant Subject., 16, 91-138.

_ 1996: Q methodology and qualitative research. Qual. Health Res., 6, 561-567, https://doi.org/10.1177/104973239600600408.

Bumbudsanpharoke, W., D. Moran, and C. Hall, 2009: Exploring perspectives of environmental best management practices in Thai agriculture: An application of Q-methodology. Environ. Conserv., 36, 225-234, https://doi.org/10.1017/S0376892909990397.

Burke, M., D. Ockwell, and L. Whitmarsh, 2018: Participatory arts and affective engagement with climate change: The missing link in achieving climate compatible behaviour change? Global Environ. Change, 49, 95-105, https://doi.org/10.1016/ j.gloenvcha.2018.02.007.

Burton, I., S. Huq, B. Lim, O. Pilifosova, and E. L. Schipper, 2002: From impacts assessment to adaptation priorities: The shaping of adaptation policy. Climate Policy, 2, 145-159, https://doi.org/ 10.3763/cpol.2002.0217.
Caney, S., 2005: Cosmopolitan justice, responsibility, and global climate change. Leiden J. Int. Law, 18, 747-775, https://doi.org/ 10.1017/S0922156505002992.

Capstick, S., C. Demski, R. Sposato, N. Pidgeon, A. Spence, and A. Corner, 2015: Public perceptions of climate change in Britain following the winter 2013/2014 flooding. Understanding Risk Research Group Working Paper 15-01, 71 pp., http://psych.cf.ac.uk/ understandingrisk/reports/URG\%2015-01\%20WinterFlooding.pdf.

Carson, M., A. Köhl, D. Stammer, A. B. A. Slangen, C. A. Katsman, R. S. W. van de Wal, J. Church, and N. White, 2016: Coastal sea level changes, observed and projected during the 20th and 21st century. Climatic Change, 134, 269-281, https:// doi.org/10.1007/s10584-015-1520-1.

Challinor, A. J., J. Watson, D. Lobell, S. Howden, D. Smith, and N. Chhetri, 2014: A meta-analysis of crop yield under climate change and adaptation. Nat. Climate Change, 4, 287-291, https://doi.org/10.1038/nclimate2153.

Chappin, E. J., and T. van der Lei, 2014: Adaptation of interconnected infrastructures to climate change: A socio-technical systems perspective. Util. Policy, 31, 10-17, https://doi.org/ 10.1016/j.jup.2014.07.003.

Chilvers, J., I. Lorenzoni, G. Terry, P. Buckley, J. K. Pinnegar, and S. Gelcich, 2014: Public engagement with marine climate change issues: $(\mathrm{Re})$ framings, understandings and responses. Global Environ. Change, 29, 165-179, https://doi.org/10.1016/ j.gloenvcha.2014.09.006.

Chong, D., and J. N. Druckman, 2007: Framing theory. Annu. Rev. Polit. Sci., 10, 103-126, https://doi.org/10.1146/annurev. polisci.10.072805.103054.

Clar, C., A. Prutsch, and R. Steurer, 2013: Barriers and guidelines for public policies on climate change adaptation: A missed opportunity of scientific knowledge-brokerage. Nat. Resour. Forum, 37, 1-18, https://doi.org/10.1111/1477-8947.12013.

Clark, P. U., and Coauthors, 2016: Consequences of twenty-firstcentury policy for multi-millennial climate and sea-level change. Nat. Climate Change, 6, 360-369, https://doi.org/10.1038/ nclimate2923.

Coogan, J., and N. Herrington, 2011: Q-methodology: An overview. Res. Second. Teacher Educ., 1, 24-28.

Cotton, M., 2015: Stakeholder perspectives on shale gas fracking: A Q-method study of environmental discourses. Environ. Plann., 47A, 1944-1962, https://doi.org/10.1177/0308518X15597134. and P. Devine-Wright, 2011: Discourses of energy infrastructure development: A Q-method study of electricity line siting in the UK. Environ. Plann., 43A, 942-960, https:// doi.org/10.1068/a43401.

Cross, R. M., 2005: Exploring attitudes: The case for Q methodology. Health Educ. Res., 20, 206-213, https://doi.org/10.1093/ her/cyg121.

Cuppen, E., S. Breukers, M. Hisschemöller, and E. Bergsma, 2010: Q methodology to select participants for a stakeholder dialogue on energy options from biomass in the Netherlands. Ecol. Econ., 69, 579-591, https://doi.org/10.1016/ j.ecolecon.2009.09.005.

Dasgupta, P., 2005: "Q methodology" for mapping stakeholder perceptions in participatory forest management. U.K. Department for International Development Project R8280 Rep., 43 pp., https://www.geog.cam.ac.uk/research/projects/harda/reports/ B3-QReport.pdf.

Deryng, D., D. Conway, N. Ramankutty, J. Price, and R. Warren, 2014: Global crop yield response to extreme heat stress under multiple climate change futures. Environ. Res. Lett., 9, 034011, https://doi.org/10.1088/1748-9326/9/3/034011. 
Döll, P., and Coauthors, 2015: Integrating risks of climate change into water management. Hydrol. Sci. J., 60, 4-13, https://doi.org/ 10.1080/02626667.2014.967250.

Dryzek, J. S., 1990: Discursive Democracy: Politics, Policy and Political Science. Cambridge University Press, 264 pp.

Durning, D., 1999: The transition from traditional to postpositivist policy analysis: A role for Q-methodology. J. Policy Anal. Manage., 18, 389-410, https://doi.org/10.1002/(SICI)1520-6688(199922) 18:3<389::AID-PAM4>3.0.CO;2-S.

Eisenack, K., S. C. Moser, E. Hoffmann, R. J. T. Klein, C. Oberlack, A. Pechan, M. Rotter, and C. J. A. M. Termeer, 2014: Explaining and overcoming barriers to climate change adaptation. Nat. Climate Change, 4, 867-872, https://doi.org/10.1038/ nclimate2350.

Frisch, D., 1993: Reasons for framing effects. Organ. Behav. Hum. Decis. Process., 54, 399-429, https://doi.org/10.1006/ obhd.1993.1017.

Geneletti, D., and L. Zardo, 2016: Ecosystem-based adaptation in cities: An analysis of European urban climate adaptation plans. Land Use Policy, 50, 38-47, https://doi.org/10.1016/ j.landusepol.2015.09.003.

Gieryn, T. F., 1999: Cultural Boundaries of Science: Credibility on the Line. Chicago University Press, 398 pp.

Goebbert, K., H. C. Jenkins-Smith, K. Klockow, M. C. Nowlin, and C. L. Silva, 2012: Weather, climate, and worldviews: The sources and consequences of public perceptions of changes in local weather patterns. Wea. Climate Soc., 4, 132-144, https:// doi.org/10.1175/WCAS-D-11-00044.1.

Hoppe, R., 2010: Lost in translation? A boundary work perspective on making climate change governable. From Climate Change to Social Change: Perspectives on Science-Policy Interactions, P. P. J. Driessen, P. Leroy, and W. van Vierssen, Eds., Earthscan, 109-130.

Howell, R. A., S. Capstick, and L. Whitmarsh, 2016: Impacts of adaptation and responsibility framings on attitudes towards climate change mitigation. Climatic Change, 136, 445-461, https://doi.org/10.1007/s10584-016-1627-z.

Hulme, M., 2009: Why We Disagree about Climate Change: Understanding Controversy, Inaction and Opportunity. Cambridge University Press, 428 pp.

Hutson, G., D. Montgomery, and L. Caneday, 2010: Perceptions of outdoor recreation professionals toward place meanings in natural environments: A Q-method inquiry. J. Leisure Res., 42, 417-442, https://doi.org/10.1080/00222216.2010.11950212.

Kaspersen, P. S., N. Høegh Ravn, K. Arnbjerg-Nielsen, H. Madsen, and M. Drews, 2017: Comparison of the impacts of urban development and climate change on exposing European cities to pluvial flooding. Hydrol. Earth Syst. Sci., 21, 4131-4147, https://doi.org/10.5194/hess-21-4131-2017.

Khan, S. J., D. Deere, F. D. Leusch, A. Humpage, M. Jenkins, and D. Cunliffe, 2015: Extreme weather events: Should drinking water quality management systems adapt to changing risk profiles? Water Res., 85, 124-136, https://doi.org/10.1016/ j.watres.2015.08.018.

Kundzewicz, Z. W., and Coauthors, 2014: Flood risk and climate change: Global and regional perspectives. Hydrol. Sci. J., 59, 1-28, https://doi.org/10.1080/02626667.2013.857411.

Lakoff, G., 2010: Why it matters how we frame the environment. Environ. Commun., 4, 70-81, https://doi.org/10.1080/ 17524030903529749.

Lavorel, S., and Coauthors, 2015: Ecological mechanisms underpinning climate adaptation services. Global Change Biol., 21, 12-31, https://doi.org/10.1111/gcb.12689.
Leith, P., 2011: Public engagement with climate adaptation: An imperative for (and driver of) institutional reform? Engaging the Public with Climate Change: Behaviour Change and Communication, L. Whitmarsh, S. O'Neill, and I. Lorenzoni, Eds., Routledge Earthscan, 100-119.

Lindberg, F., S. Thorsson, D. Rayner, and K. Lau, 2016: The impact of urban planning strategies on heat stress in a climate-change perspective. Sustainable Cities Soc., 25, 1-12, https://doi.org/ 10.1016/j.scs.2016.04.004.

Linderholm, H. W., 2006: Growing season changes in the last century. Agric. For. Meteor., 137, 1-14, https://doi.org/10.1016/ j.agrformet.2006.03.006.

Lo, A. Y., 2016: Public discourses of climate change in Hong Kong. J. Environ. Policy Plann., 18, 27-46, https://doi.org/10.1080/ 1523908X.2015.1040545.

— on local weather change and differential effects on climate change attitude. Public Underst. Sci., 24, 928-942, https://doi.org/ 10.1177/0963662513517483.

Lorenzoni, I., S. Nicholson-Cole, and L. Whitmarsh, 2007: Barriers perceived to engaging with climate change among the UK public and their policy implications. Global Environ. Change, 17, 445-459, https://doi.org/10.1016/j.gloenvcha.2007.01.004.

Martin, G. P., 2008: 'Ordinary people only': Knowledge, representativeness, and the publics of public participation in healthcare. Sociol. Health Illn., 30, 35-54, https://doi.org/ 10.1111/j.1467-9566.2007.01027.x.

McEvoy, D., P. Matczak, I. Banaszak, and A. Chorynski, 2010: Framing adaptation to climate-related extreme events. Mitig. Adapt. Strategies Global Change, 15, 779-795, https://doi.org/ 10.1007/s11027-010-9233-2.

McKeown, B., and D. Thomas, 1988: Q Methodology. SAGE, $83 \mathrm{pp}$.

McLaughlin, D. M., and B. B. Cutts, 2018: Neither knowledge deficit nor NIMBY: Understanding opposition to hydraulic fracturing as a nuanced coalition in Westmoreland County, Pennsylvania (USA). Environ. Manage., 62, 305-322, https:// doi.org/10.1007/s00267-018-1052-3.

McNeeley, S. M., and H. Lazrus, 2014: The cultural theory of risk for climate change adaptation. Wea. Climate Soc., 6, 506-519, https://doi.org/10.1175/WCAS-D-13-00027.1.

Meadow, A. M., D. B. Ferguson, Z. Guido, A. Horangic, G. Owen, and T. Wall, 2015: Moving toward the deliberate coproduction of climate science knowledge. Wea. Climate Soc., 7, 179-191, https://doi.org/10.1175/WCAS-D-14-00050.1.

Moser, S. C., 2012: Adaptation, mitigation, and their disharmonious discontents: An essay. Climatic Change, 111, 165-175, https://doi.org/10.1007/s10584-012-0398-4.

_ 2014: Communicating adaptation to climate change: The art and science of public engagement when climate change comes home. Wiley Interdiscip. Rev.: Climate Change, 5, 337-358, https://doi.org/10.1002/wcc.276.

— climate change adaptation. Proc. Natl. Acad. Sci. USA, 107, 22 026-22 031, https://doi.org/10.1073/pnas.1007887107.

Neff, M. W., 2014: Research prioritization and the potential pitfall of path dependencies in coral reef science. Minerva, 52, 213 235, https://doi.org/10.1007/s11024-014-9250-5.

Nisbet, M. C., 2009: Communicating climate change: Why frames matter for public engagement. Environment, 51, 12-23, https:// doi.org/10.3200/ENVT.51.2.12-23.

O'Brien, K., S. Eriksen, L. P. Nygaard, and A. Schjolden, 2007: Why different interpretations of vulnerability matter in climate 
change discourses. Climate Policy, 7, 73-88, https://doi.org/ 10.1080/14693062.2007.9685639.

O'Neill, S., and S. Nicholson-Cole, 2009: "Fear won't do it": Promoting positive engagement with climate change through visual and iconic representations. Sci. Commun., 30, 355-379, https://doi.org/10.1177/1075547008329201.

— M. Boykoff, S. Niemeyer, and S. A. Day, 2013: On the use of imagery for climate change engagement. Global Environ. Change, 23, 413-421, https://doi.org/10.1016/j.gloenvcha.2012.11.006.

Otto-Banaszak, I., P. Matczak, J. Wesseler, and F. Wechsung, 2011: Different perceptions of adaptation to climate change: A mental model approach applied to the evidence from expert interviews. Reg. Environ. Change, 11, 217-228, https://doi.org/ 10.1007/s10113-010-0144-2.

Paavola, J., and W. N. Adger, 2006: Fair adaptation to climate change. Ecol. Econ., 56, 594-609, https://doi.org/10.1016/ j.ecolecon.2005.03.015.

Pacifici, M., and Coauthors, 2015: Assessing species vulnerability to climate change. Nat. Climate Change, 5, 215-224, https:// doi.org/10.1038/nclimate2448.

Pecl, G. T., and Coauthors, 2017: Biodiversity redistribution under climate change: Impacts on ecosystems and human well-being. Science, 355, eaai9214, https://doi.org/10.1126/ science.aai9214.

Pelling, M., 2010: Adaptation to Climate Change: From Resilience to Transformation. Routledge, $224 \mathrm{pp}$.

Porter, J. J., D. Demeritt, and S. R. Dessai, 2015: The right stuff? Informing adaptation to climate change in British local government. Global Environ. Change, 35, 411-422, https://oi.org/ 10.1016/j.gloenvcha.2015.10.004.

Rajamani, L., 2000: The principle of common but differentiated responsibility and the balance of commitments under the climate regime. Rev. Eur. Community Int. Environ. Law, 9, 120 131, https://doi.org/10.1111/1467-9388.00243.

Rayner, S., 2010: How to eat an elephant: A bottom-up approach to climate policy. Climate Policy, 10, 615-621, https://doi.org/ 10.3763/cpol.2010.0138.

Riebesell, U., and J.-P. Gattuso, 2015: Lessons learned from ocean acidification research. Nat. Climate Change, 5, 12-14, https:// doi.org/10.1038/nclimate2456.

Robbins, P., and R. Kreuger, 2000: Beyond bias? The promise and limits of Q method in human geography. Prof. Geogr., 52, 636648, https://doi.org/10.1111/0033-0124.00252.

Schreurs, M. A., 2008: From the bottom up: Local and subnational climate change politics. J. Environ. Dev., 17, 343-355, https:// doi.org/10.1177/1070496508326432.

Shackley, S., and B. Wynne, 1996: Representing uncertainty in global climate change science and policy: Boundary-ordering devices and authority. Sci. Technol. Human Values, 21, 275302, https://doi.org/10.1177/016224399602100302.

Smith, L. C., and S. R. Stephenson, 2013: New Trans-Arctic shipping routes navigable by midcentury. Proc. Natl. Acad. Sci. USA, 110, E1191-E1195, https://doi.org/10.1073/ pnas.1214212110.

Spence, A., W. Poortinga, and N. Pidgeon, 2012: The psychological distance of climate change. Risk Anal., 32, 957-972, https:// doi.org/10.1111/j.1539-6924.2011.01695.x.

Spurgeon, L., G. Humphreys, G. James, and C. Sackley, 2012: A Q-methodology study of patients' subjective experiences of TIA. Stroke Res. Treat., 2012, 486261, https://doi.org/10.1155/ 2012/486261.

Steelman, T. A., and L. A. Maguire, 1999: Understanding participant perspectives: Q-methodology in national forest management
J. Policy Anal. Manage., 18, 361-388, https://doi.org/10.1002/ (SICI)1520-6688(199922)18:3<361::AID-PAM3>3.0.CO;2-K.

Stephenson, W., 1953: The Study of Behavior: Q-Technique and Its Methodology. University of Chicago Press, $376 \mathrm{pp}$.

Stevenson, H., 2015: Contemporary discourses of green political economy: A Q method analysis. J. Environ. Policy Plann., https:// doi.org/10.1080/1523908X.2015.1118681.

Storbjörk, S., 2007: Governing climate adaptation in the local arena: Challenges of risk management and planning in Sweden. Local Environ., 12, 457-469, https://doi.org/10.1080/ 13549830701656960.

Stott, P. A., and Coauthors, 2016: Attribution of extreme weather and climate-related events. Wiley Interdiscip. Rev.: Climate Change, 7, 23-41, https://doi.org/10.1002/wcc.380.

Thomas, D. B., and L. R. Baas, 1992: The issue of generalization in Q methodology: "Reliable schematics" revisited. Operant Subject., 16, 18-36, https://doi.org/10.15133/j.os.1992.014.

Tielen, M., A. L. van Staa, S. Jedeloo, N. J. A. van Exel, and W. Weimar, 2008: Q-methodology to identify young adult renal transplant recipients at risk for nonadherence. Transplantation, 85, 700-706, https://doi.org/10.1097/TP.0b013e318166163e.

Trenberth, K. E., A. Dai, G. van der Schrier, P. D. Jones, J. Barichivich, K. R. Briffa, and J. Sheffield, 2014: Global warming and changes in drought. Nat. Climate Change, 4, 17-22, https://doi.org/10.1038/nclimate2067.

Tubergen, G. N., and R. A. Olins, 1979: Mail vs. personal interview administration for Q-sorts: A comparative study. Operant Subject., 2, 51-59.

Urban, M. C., 2015: Accelerating extinction risk from climate change. Science, 348, 571-573, https://doi.org/10.1126/science. aaa4984.

Urwin, K., and A. Jordan, 2008: Does public policy support or undermine climate change adaptation? Exploring policy interplay across different scales of governance. Global Environ. Change, 18, 180-191, https://doi.org/10.1016/j.gloenvcha.2007.08.002.

van Aalst, M. K., T. Cannon, and I. Burton, 2008: Community level adaptation to climate change: The potential role of participatory community risk assessment. Global Environ. Change, 18, 165179, https://doi.org/10.1016/j.gloenvcha.2007.06.002.

van Exel, J., and G. de Graaf, 2005: Q methodology: A sneak preview. Tech Rep., 30 pp., https://qmethodblog.files.wordpress.com/2016/ 01/qmethodologyasneakpreviewreferenceupdate.pdf.

Venables, D., N. Pidgeon, P. Simmons, K. Henwood, and K. Parkhill, 2009: Living with nuclear risk: A Q-method study. Risk Anal., 29, 1089-1104, https://doi.org/10.1111/j.15396924.2009.01259.x.

Voskamp, I., and F. Van de Ven, 2015: Planning support system for climate adaptation: Composing effective sets of blue-green measures to reduce urban vulnerability to extreme weather events. Build. Environ., 83, 159-167, https://doi.org/10.1016/ j.buildenv.2014.07.018.

Watts, N., and Coauthors, 2015: Health and climate change: Policy responses to protect public health. Lancet, 386, 1861-1914, https://doi.org/10.1016/S0140-6736(15)60854-6.

Watts, S., and P. Stenner, 2005: Doing Q methodology: Theory, method and interpretation. Qual. Res. Psychol., 2, 67-91, https://doi.org/10.1191/1478088705qp022oa. , and - 2012: Doing Q Methodological Research: Theory, Method \& Interpretation. SAGE, 248 pp.

Webler, T., S. Danielson, and S. Tuler, 2009: Using Q method to reveal social perspectives in environmental research. Social and Environmental Research Institute Doc., 55 pp., http:// www.seri-us.org/sites/default/files/Qprimer.pdf. 
Weingart, P., A. Engels, and P. Pansegrau, 2000: Risks of communication: Discourses on climate change in science, politics, and the mass media. Public Underst. Sci., 9, 261-283, https:// doi.org/10.1088/0963-6625/9/3/304.

Whyte, K. P., 2013: Justice forward: Tribes, climate adaptation and responsibility. Climate Change and Indigenous Peoples in the United States, J. K. Maldonado, B. Colombi, and R. Pandya, Eds., Springer, 9-22.

Wise, R. M., I. Fazey, M. Stafford-Smith, S. E. Park, H. C. Eakin, E. R. M. Archer Van Garderen, and B. Campbell, 2014: Reconceptualising adaptation to climate change as part of pathways of change and response. Global Environ. Change, 28, 325-336, https://doi.org/10.1016/j.gloenvcha.2013.12.002.

Wolf, J., and S. C. Moser, 2011: Individual understandings, perceptions, and engagement with climate change: Insights from in-depth studies across the world. Wiley Interdiscip. Rev.: Climate Change, 2, 547-569, https://doi.org/10.1002/ wcc. 120.

Wolsink, M., 2010: Discourses on the implementation of wind power: Stakeholder views on public engagement. Renewable Energy and the Public: From NIMBY to Participation, P. Devine-Wright, Ed., Earthscan, 75-87. 